\title{
Consequentes de atitudes de vingança: novos olhares sobre os aspectos negativos no comportamento do consumidor
}

\author{
Consequential of behaviors vindictive: new \\ perspectives about the negative aspects in consumer \\ behavior
}

\author{
Ana Paula Benício da Rocha ${ }^{1}$ \\ Simony Rodrigues Marins ${ }^{2}$ \\ Márcio de Oliveira Mota ${ }^{3}$ \\ Ana Augusta Ferreira de Freitas ${ }^{4}$
}

\section{Resumo}

Este artigo busca analisar o comportamento de consumidores após atitudes de vingança, a fim de identificar seus potenciais consequentes. Para tanto, foi feito um estudo exploratório, de natureza qualitativa, por meio de entrevistas estruturadas, além de um grupo focal com praticantes de ações vingativas. Os dados foram interpretados pela técnica da análise temática. Dentre os principais resultados estão o desejo e as atitudes de afastamento, seguidas pela procura de empresas concorrentes. A ineficácia de instrumentos judiciais frente à defesa de consumidores foi marcante, sendo os mecanismos virtuais grandes canais para o resgate da equidade na relação por parte dos consumidores.

Palavras-chave: Consequentes. Atitudes vingativas. Serviços. Comportamento do Consumidor.

\footnotetext{
Mestranda em Administração no Curso de Mestrado Acadêmico em Administração Universidade Estadual do Ceará (CMAAd/UECE). E-mail: anapaulabenicio@hotmail.com

2 Mestranda em Administração no Curso de Mestrado Acadêmico em Administração Universidade Estadual do Ceará (CMAAd/UECE). E-mail: simonymarins@gmail.com

3 Doutor em Administração pela UNIFOR. Professor efetivo do Curso de Mestrado Acadêmico em Administração - Universidade Estadual do Ceará (CMAAd/UECE). E-mail: marcio@marciomota. com

4 Pós-doutorado em Administração pela EBAPE-FGV. Professora efetiva do Curso de Mestrado Acadêmico em Administração - Universidade Estadual do Ceará (CMAAd/UECE). E-mail: freitas8@terra.com.br
} 


\section{Abstract}

This article aimed to analyze the behavior of consumers after behaviors of revenge in order to identify their potential consequential. An exploratory qualitative study using structured interviews was done, and a focus group with practitioners of retaliatory actions. The data were interpreted by the technique of thematic analysis. Among the main results are the desire and behaviors of avoidance, followed by demand from competing companies. The ineffectiveness of legal instruments against the defense of consumers was remarkable, and the major mechanisms virtual channels to the rescue of fairness in the relationship on the part of consumers.

Keywords: Consequential. Vindictive Behaviors.Services. ConsumerBehavior.

\section{Introdução}

A literatura indica uma série de reações a partir da insatisfação e percepção de injustiça durante as relações de troca na compra de produtos e/ou serviços quando conduzidas de forma malsucedida, sendo influenciadas pela raiva e/ou desejo de vingança em menor ou maior grau (HUEFNER; HUNT, 2000; HUEFNER et al., 2002; BECHWATI; MORRIN, 2003; ZOURRIG; CHEBAT; TOFFOLLI, 2009; FUNCHES; MARKLEY; DAVIS, 2009; GREGOIRE; LAUFER; TRIPP, 2009; THELEN; SHAPIRO, 2012; HOPKINS, 2013; JOIREMAN et al., 2013; LEE; PAN; TSAI, 2013; BOUGIE et al.,2003). Essas reações têm desencadeado ações cada vez mais danosas à imagem das empresas, pois através da acessibilidade fornecida pela internet, em ambientes específicos ou não, como as redes sociais, emoções negativas originadas durante experiências de consumo malsucedidas são transmitidas para um grupo maior de pessoas (e.g. boca a boca negativo), o que oferece aos consumidores maior sensação de empoderamento (WARD; OSTROM, 2006; ALBUQUERQUE et al., 2011; ANDRADE; BRANDÃO, 2012; ANDRADE et al., 2013).

Diversos autores apontam a necessidade de se investigar aspectos negativos do comportamento do consumidor, além de salientar a vingança como ação relativamente pouco estudada, mas importante fenômeno comportamental (CRONIN, 2003; BECHWATI; MORRIN, 2003; FUNCHES et al., 2009). São, portanto, de extrema relevância 
estudos que explorem os diversos aspectos componentes do fenômeno que permeiam os atos vingativos por parte de consumidores, a fim de oferecer às empresas oportunidade de melhorias nos processos de trocas comerciais e em suas estruturas de relacionamento com os clientes. Consumidores também serão diretamente beneficiados, visto que uma melhor compreensão de seus pensamentos, sentimentos e ações pode acarretar em melhores produtos e serviços ofertados pelas empresas e, consequentemente, reduzir a possibilidade de atitudes de vingança.

Na última década, embora tenha ocorrido um crescimento desses estudos, principalmente em campo internacional, no Brasil, poucos autores têm se empenhado em identificar os fatores que interferem em processos de vingança. Os objetos de estudo são predominantemente aqueles que evidenciam as razões originadoras e as formas como atitudes vingativas se manifestam, limitados a ambientes virtuais de compra e/ou manifestações de reclamação. Há, assim, uma lacuna para aprofundamento em situações reais de compra, além do estudo sobre seus consequentes (GIGLIO; CHAUVEL, 2002, FERNANDES; SANTOS, 2008, SANTOS; FERNANDES, 2010, ALBUQUERQUE; PEREIRA; BELLINI, 2010, ANDRADE et al., 2010, ANDRADE; BRANDÃO, 2012, ANDRADE; BRANDÃO; BALASSIANO, 2013).

De maneira específica, poucos estudos com o objetivo de evidenciar quais comportamentos dos consumidores após esses anos foram observados no contexto internacional, a saber, Joireman et al. (2013) e Hopkins (2013). No Brasil, porém, ainda não há estudos dessa natureza. Tendo em vista tal lacuna, pretende-se responder à seguinte questão de pesquisa: qual o comportamento de consumidores após atitudes de vingança? Para tanto, este estudo objetivou analisar o comportamento de consumidores após atitudes de vingança, a fim de identificar seus potenciais consequentes.

No intuito de atingir o objetivo proposto, foi feito um estudo exploratório, de natureza qualitativa, com a realização de entrevistas por meio virtual e da técnica de um grupo focal com consumidores de produtos 
e serviços. Os dados foram tratados por meio da análise temática. A seguir, será evidenciada a literatura sobre as temáticas de vingança, seus antecedentes e consequentes, os aspectos metodológicos, os resultados da pesquisa e, ao final, as respectivas discussões e considerações.

\section{Referencial teórico}

Torna-se necessário evidenciar estudos prévios sobre os fatores que contribuem para as ações de vingança - fatores estes relacionados à cognição, emoção e comportamento (GRÉGOIRE et al., 2010; ANDRADE et al., 2013).

\section{Antecedentes de atitudes de vingança}

Quanto a aspectos de cognição, a percepção de injustiça seria o principal gatilho para o desencadeamento de emoções e consequentes ações negativas no comportamento do consumidor. A justiça envolve a adequação das decisões e possui visão conceitual em três dimensões: a justiça distributiva (lida com os resultados da decisão), a justiça processual (lida com processos de decisão) e a justiça internacional (lida com comportamento interpessoal na promulgação dos procedimentos e entrega de resultados) (TAX et al.,1998). Essas três dimensões, junto com a atribuição de culpa (GREGOIRE; FISHER, 2008; GREGOIRE et al.,2009; GREGOIRE et al., 2010), são citadas como cognições do cliente sobre as atitudes da empresa.

Para Bechwati e Morrin (2003), níveis de percepção de justiça interacional desencadeiam ações mais vingativas que níveis de percepção de justiça distributiva. Assim, a percepção de mau tratamento (percepção de injustiça interacional), por exemplo, desencadearia maior comportamento de vingança que os resultados de uma reclamação (como gatilhos para o sentimento de vingança - percepção de justiça distributiva). Ainda para os autores, a injustiça processual é também forte antecedente de desejo de vingança pelo consumidor. Quanto às emoções negativas que antecedem atitudes de vingança, faz-se 
necessário conceituar os constructos de raiva, desejo de vingança e insatisfação.

Segundo pesquisa desenvolvida por Bougie et al. (2003), a raiva é um poderoso antecedente de respostas comportamentais dos consumidores à falha do serviço, ou seja, encontra-se para além do efeito de insatisfação, como indicam Huefnet e Hunt (2000). Para Kalama et al. (2008), à medida que aumenta a intensidade da raiva e demais emoções negativas correlatas, há também o aumento da propensão dos consumidores a cobrar e agir propositadamente de forma danosa à empresa.

Para Bougie et al. (2003), atos vingativos tendem a ser desencadeados pela raiva, a qual atua como mediadora de tais atitudes. A raiva é uma resposta emocional negativa mais geral, que pode ter diversos destinos e muitos modos possíveis de expressão (STUCKLESS et al., 1995). Funches (2011) a conceitua como um estado emocional que decorre de perda de percepção do consumidor de direito, devido a uma experiência de consumo injusta, ameaçadora ou prejudicial. Essas experiências de consumo envolvem interações com a empresa, seus produtos, serviços e funcionários. A raiva pode ser subdividida em três categorias de principais causadores: promessas quebradas (serviço pobre, erros de funcionários e falhas de respostas), tratamento injusto (situações que favorecem excessivamente a empresa) e expressão de hostilidade.

Bechwatie e Morrin (2003) complementam tais estudos ao apresentarem o desejo de vingança como outra forte emoção mediadora (em inglês, DCV - Desire for Consumer Vengeance), sendo os sentimentos retaliatórios o desejo de exercer algum dano à empresa, normalmente após uma experiência de compra extremamente negativa. Dessa forma, o desejo de vingança difere de uma grave insatisfação do cliente, pois incorpora a intenção de agir. É também diferente da raiva intensa (ou raiva), pois é menos espontâneo e mais intencionalmente planejado (BEACHWATI; MORRIN, 2003, 2007). 
Portanto, o desejo por vingança é, juntamente com a raiva, um importante antecedente de atitudes vingativas por parte dos consumidores, alimentando a necessidade de causar dano, prejuízo, desconforto, punição, ou simplesmente pressionar a empresa, a fim de restabelecer a equidade psicológica (HUEFNER; HUNT, 2000; HUEFNER et al., 2002; BECHWATI; MORRIN, 2003; ANDRADE et al., 2013) ou simplesmente com a intenção de aliviar a raiva (ZOURRIG et al., 2009; BOUGIE et al., 2003).

Como comportamentos, Funches (2011) alerta para proposições de danos às empresas provenientes de sentimento de raiva que vão muito além do simples rompimento da relação comercial (afastamento), as quais são ainda mais difíceis de detectar e, por conseguinte, dão espaço para o crescimento de empresas concorrentes. Pode-se citar como exemplos de danos causados por clientes vingativos a redução de gastos com a empresa, incluindo a não recompra de determinados produtos ou serviços, mudança de localização para outra filial da empresa, ou até mesmo o afastamento de determinados funcionários. De forma geral, esses clientes reduzem a tolerância a erros futuros ou simplesmente ainda não encontraram alternativa de escolha no mercado. Com o intuito de oportunizar uma melhor compreensão do fenômeno "vingança do consumidor", o presente estudo explorará o conceito de vingança e as atitudes vingativas no contexto de trocas comerciais.

\section{Vingança do consumidor}

A psicologia aborda a vingança como uma inflição de um mal, em troca de uma percepção de um dano sofrido, cujo objetivo principal é aliviar o vingador de um sentimento desconfortável (como a raiva). Não é necessariamente racional e pode ocasionar agressão futura, de forma direta ou indireta, quando do retorno posterior de atitudes vingativas (STUCKLESS; GORANSON, 1992).

Vero (2006) define vingança como um ato que, para materializarse, pressupõe algumas pulsões (desejo e perda), entretém algo de paixão e implica em graus variados de pensamentos (já que exige o 
mínimo de planejamento para sua execução). A autora complementa afirmando que quando a pessoa se sente atraída de maneira vital, de forma a colocar em risco sua integridade, ela pode "maquinar" alguma vingança. Entregar-se ao prazer de elucubrar maneiras de se vingar passa, então, a ocupar o pensamento. Assim, a agressão da qual a pessoa se sentiu vítima num primeiro momento desencadearia uma depressão crescente até o momento em que a vingança seria uma das maneiras de reações possíveis, pois, através de uma ação vingativa, novas energias começam a circular, pondo em movimento o aparelho psíquico, de maneira a fazer aquela subjetividade sentir-se novamente viva (VERO, 2006).

Como se vê, não há exatidão quanto ao grau de racionalidade em atitudes de vingança. Diferentes graus de racionalidade podem implicar em diferenças quanto ao planejamento ou espontaneidade de atitudes. Reside aqui a importância dos constructos emocionais da raiva (como algo mais espontâneo e menos racional) e o desejo de vingança (como algo menos espontâneo e mais intencionalmente planejado), como discutido anteriormente.

A literatura apresenta, ainda, divergências na interpretação dos constructos "vingança" e "retaliação", os quais ora são sinônimos (ROSSI, 2011; BECHWATI; MORRIN, 2003; HUEFNER; HUNT, 2000), ora são diferenciados quanto à racionalidade, afeto e comportamento (STUCKLESS; GORANSON, 1992; ALBUQUERQUE et al., 2011; ANDRADE et al., 2013). Com o intuito de clarificar essa divergência, recorreu-se ao Dicionário Houaiss, no qual a definição de "retaliação" é equivalente a revide com dano igual ao sofrido e/ou vingar a agressão ou ofensa sofridas; já a palavra "vingança" é definida como ato lesivo praticado em nome próprio ou alheio, por alguém que foi real ou presumidamente ofendido ou lesado, em represália contra aquele que é ou seria causador do dano, ou seja, o equivalente a castigo, pena ou punição. Por tais definições, também não há diferenças entre os constructos. 
Partindo-se dessas reflexões, o presente estudo opta por compreender a vingança como um constructo de maior força, embora abranja atitudes de retaliação. As ações retaliatórias seriam, portanto, ações vingativas influenciadas por valências negativas, em um estado menor de intensidade de raiva e maior racionalidade. A intensidade pode evoluir a estágios de raiva e desejos de vingança maiores, originando ações vingativas mais extremas. As tendências culturais alocêntrica e idiocêntrica, bem como idade, nível instrucional, renda e gênero (ZOURRIG et al., 2009; HUEFNER; HUNT, 2000) e personalidade (FUNCHES et al. 2009) seriam moderadores capazes de atenuar ou aumentar tais valências. Dessa forma, ambos os comportamentos estariam dispostos a causar algum dano à empresa, proporcionando sentimentos de retribuição psicológica ou alívio da raiva pelo consumidor (ZOURRIG et al., 2009; ZOURRIG, 2010; BEACHWATI; MORRIN, 2003; HUEFNER; HUNT, 2000 e 2002; FUNCHES et al., 2009; FUNCHES, 2011).

A vingança seria uma forte tentativa de aliviar a raiva, indignação, insatisfação, injustiça ou revolta (HUEFNER; HUNT, 2000), constituindose tanto como um sentimento (ou emoção) quanto como um comportamento, e tendo como consequências emoções de satisfação, alívio, prazer, reparação psicológica (ou percepção e justiça) e sensação de felicidade. Nesse caso, quando o desejo de vingança é alto, muitos consumidores optam por deixar a empresa e escolhem empresas competidoras, mesmo que disponham de altos preços (BECHWATI; MORRIN, 2003), estando esses comportamentos caracterizados como retaliatórios ou vingativos.

$\mathrm{Na}$ retaliação, o consumidor pode manter sua relação com a empresa, porém, conforme a intensidade da raiva e o desejo de vingança aumentam, atitudes vingativas mais drásticas são tomadas pelos consumidores. Nesses casos, portanto, há maior probabilidade de afastamento (McCULLOUGH et al., 1998; GRÉGOIRE et al., 2009; GRÉGOIRE; FISHER, 2008), sendo uma resposta passiva (flight). Há ainda o enfrentamento (fight) (ZOURRIG et al., 2009), que pode ser 
mensurado em boca a boca negativo (pessoal ou eletrônico), reclamação vingativa e reclamação a terceiros (GRÉGOIRE et al., 2010).

Dentre os comportamentos, Huefner e Hunt (2000) citam como retaliatórios a criação de custos ou perdas para a empresa (esforço para causar danos financeiros à empresa), ações de vandalismo, roubo, boca a boca negativo (pessoal ou eletrônico) e ataque pessoal. Grégoire et al. (2010) subdividem os comportamentos vingativos em ações diretas e indiretas, os quais se diferenciariam pela moderação de percepção de poder do consumidor. Dessa forma, a vingança direta pode assumir a forma de reclamação vingativa quando os clientes desabafam seu descontentamento aos empregados da linha de frente, de forma a causar incômodo às operações da empresa (GRÉGOIRE; FISHER, 2008), ou usando outras formas de agressão, como danificar a propriedade de uma empresa, deliberadamente violando políticas, atingindo um objeto ou batendo a porta. Esses comportamentos formam o constructo "agressão no local de compra", definido como as ações dos clientes que são projetadas para prejudicar diretamente uma empresa ou seus funcionários. Deve-se salientar que a propensão do indivíduo a reclamar é afetada pela vergonha. De modo particular, quando a motivação para reclamar envolve desabafo, há uma tendência a evitar interação humana, o que leva o consumidor a optar por canais remotos (MATTILA; WIRTZ, 2004).

Comportamentos de vingança indiretos que tomariam forma fora das fronteiras da empresa incluem: (i) boca a boca negativo, quando os clientes em particular compartilham suas más experiências com amigos e parentes (GRÉGOIRE; FISHER, 2006); (ii) reclamação pública on-line, definida como o ato de usar aplicativos on-line para alertar o público em geral sobre o mau comportamento de uma empresa, podendo assumir formas de logomarcas, sites ou blogs para reclamação (WARD; OSTROM, 2006). A reclamação pública on-line é aqui entendida como uma forma de boca a boca negativo, posto que o ato de queixar-se a um público massivo inclui uma clara intenção de causar danos à empresa. Embora essa ameaça on-line tenha sido discutida anteriormente, esse 
comportamento tem sido raramente conceituado e medido (GRÉGOIRE et al., 2010).

Funches et al. (2009) afirmam que, ao agirem de forma vingativa, os consumidores assumem basicamente três papéis distintos do cliente (personas) enquanto cometem tais atos, são eles: vingativo (querem dar uma lição a empresa), altruísta (vontade de agir para o bem de outros) e vítima (quando os clientes sentem que eles não têm poder sobre comportamentos atuais ou futuros da empresa). Tais personas reforçam aspectos da personalidade dos clientes.

\section{Potenciais consequentes da vingança}

Para fins deste estudo, acredita-se que, após atitudes vingativas por parte dos consumidores, um novo ciclo de cognição $\rightarrow$ emoção $\rightarrow$ comportamento se inicia. No âmbito da cognição, é restabelecido o sentimento de justiça, ou até mesmo o esquecimento para a culpa atribuída.

No que concerne às emoções experimentadas, pode-se referenciar o estudo de Huefner e Hunt (2000), os quais citam as seguintes emoções desencadeadas por atitudes de vingança: excitação, ansiedade/tensão, confiança, irritação, medo, satisfação, ética/justiça, remorso, chateação e alegria. Esses autores afirmam que pessoas que fizeram boca a boca negativo, enquanto sentiam-se mais éticos sobre as atitudes vingativas previamente tomadas, também reportaram maiores níveis de irritação e geralmente se sentiam menos satisfeitos em relação aos indivíduos que experimentaram ações vingativas como vandalismo. Provavelmente, atitudes de vingança mais drásticas catalisam a raiva e frustração experimentadas, permitindo aos indivíduos se sentirem mais satisfeitos e divertidos sobre seus comportamentos antiéticos a posteriori.

Os atos de vingança, por definição, sugerem consequências para o consumidor e para a empresa. Serão observados neste estudo os seguintes constructos, alguns já observados na literatura, outros como 
possíveis achados da pesquisa e que estão relacionados à cognição, sentimentos e atitudes:

Percepção de justiça (TAX et al.,1998);

Sentimentos de alívio e satisfação: ao obter a reparação psicológica pretendida (BECHWATI; MORRIN, 2003);

Sentimento de medo: dependendo da atitude de retaliação e vingança, consumidores podem sentir medo por possíveis processos judiciais da empresa. Para Aquino et al. (2006), a assimetria do poder faz com que exista receio a ações de represália, ou seja, as vítimas parecem considerar normas sociais, bem como os aspectos práticos de se proteger de contra-retaliação por parte das empresas ofensoras. Em suma, quando as vítimas têm uma vantagem de poder sobre seus agressores e acreditam que a organização não punirá os infratores, então "fazem justiça com as próprias mãos”. Por outro lado, quando as vítimas estão em desvantagem em relação aos seus infratores, ou quando acreditam que a organização realmente punirá os infratores.

Sentimento de culpa: a literatura apresenta a culpa como um antecedente cognitivo determinante para atitudes vingativas (BECHWATI; MORRIN, 2003; 2007; GRÉGOIRE et al., 2010). Como consequentes de atos de vingança, porém, consumidores podem sentir culpa advinda da observação de exagero ou arrependimento de seus atos, ou reforçarem a atribuição de culpa à empresa ou ao funcionário.

Desejo e atitudes de afastamento: as atitudes de afastamento são citadas por McCullough et al.(1998) e Grégoire et al. (2009) como atitudes relacionadas às ações vingativas. São aqui entendidas como possíveis consequentes dos atos de vingança, pois é possível que atos de vingança, por significarem fortes emoções e atos negativos, causem desgaste no relacionamento sob a ótica do consumidor. Esse desgaste pode gerar um desejo de afastamento que antecede a atitude. $\mathrm{O}$ que pode ocorrer como consequência 
dessa atitude é a busca por concorrentes, como uma ação direta. Embora Aquino et al. (2001) e Grégoire e Fisher (2006) pontuem que os atos do consumidor com os danos gerados não chegam a caracterizar abandono ou troca da empresa, estabelece-se aqui o pressuposto de que, pelos atos de retaliação e vingança gerarem atitudes de afastamento, consumidores buscam a concorrência para obter o que precisam, mesmo para aumentar o sentimento de satisfação, estando dispostas a pagar até mais 10\% do valor em outras empresas (CARVALHO et al., 2010).

Desejo e atitudes de reconciliação: o desejo de reconciliação é tratado por Joireman et al. como a medida em que um consumidor está disposto a aceitar o fracasso de uma empresa e conceder atos de boa vontade, na esperança de manter o seu relacionamento. Em caso de novas garantias pela empresa, como preços mais baixos, promoções, principalmente para serviços com pouca concorrência ou quando o problema se refere a um funcionário, esse desejo pode ser maior. Neste estudo, insere-se o arrependimento também como possível causa do retorno do cliente, quando moderado por percepção de culpa em exagero ou sua causalidade.

\section{Estratégia metodológica}

Buscando analisar o comportamento de consumidores após atitudes de vingança, um estudo exploratório, de natureza qualitativa, foi desenvolvido. Segundo Malhotra (2012), ao adotar essa tipologia, tem-se por objetivo explorar ou fazer uma busca em um problema ou situação, a fim de oferecer informações e maior compreensão acerca de uma lacuna identificada na literatura. Como técnicas para a coleta de dados, foram utilizadas entrevistas estruturadas por meio virtual e um grupo focal.

Para as entrevistas, optou-se pelo roteiro estruturado, que, segundo Lakatos e Marconi (2003), trata-se de um roteiro pré-definido, com perguntas pré-determinadas, cujos entrevistados são previamente selecionados, sem liberdade para inserção de perguntas pelo pesquisador 
durante a aplicação. Os temas articulados no roteiro refletem os objetivos da pesquisa e buscam identificar: (a) contexto de realização de atitudes de vingança (quando eram solicitadas informações de empresa, se serviço ou produto, período do acontecimento - por meio de relato da experiência); (b) motivos dos comportamentos vingativos (processo de tomada de decisão); (c) sentimentos provocados pela atitude da empresa; (d) atitudes realizadas pelo consumidor; (e) sentimentos após atos vingativos; e (f) reversibilidade da decisão (possibilidade de voltar atrás na decisão tomada). Todas essas informações se faziam necessárias para a compreensão do contexto de análise, embora apenas os itens (d), (e) e (f) façam parte desse universo de aprofundamentos. Não foram usados os termos "retaliação e/ou vingança", sendo apenas solicitado que fossem indicadas ações que agissem contra a empresa como parte de uma insatisfação, injustiça ou problema ocorrido.

A amostra das entrevistas constou de 15 consumidores que já tinham se empenhado em atitudes de vingança com empresas de produtos ou serviços, e ocorreu entre os meses de novembro e dezembro de 2013. Dentre o perfil dos entrevistados, foram cinco homens e dez mulheres, a faixa etária compreendida entre 23 e 50 anos, com diferentes níveis de renda (de dois a dez salários mínimos mensais) e escolar (nível superior e pós-graduação).

Um grupo focal foi utilizado como técnica complementar. Segundo Freitas e Oliveira (2006), essa técnica consiste na entrevista em profundidade de forma coletiva, cuja interação se evidencia como um diferencial para a obtenção de informações e cuja quantidade suficiente de entrevistados varia dentre o limite mínimo de quatro e máximo de doze pessoas. Os participantes tinham em comum o fato de já terem praticados atitudes com o objetivo de gerar danos a empresas em retaliação a uma percepção de injustiça. O grupo focal foi realizado com cinco participantes, sendo utilizados gravadores de áudio e vídeo.

A duração do grupo ficou entre uma hora e meia e duas horas, cessando quando se observou a saturação das informações para aquele grupo. Tal grupo contou com participantes de idades entre 25 e 56 anos, todos com nível superior. Quanto ao gênero, eram dois homens e três 
mulheres, e suas rendas variavam entre dois e dez salários mínimos mensais. Os critérios de análise foram os mesmos utilizados na entrevista, com adição da observação das emoções dos participantes em relato às suas experiências e em interação em grupo. Os problemas relatados estão dentro do período de dois anos.

Para análise dos dados, foi utilizada a técnica da análise temática, que se insere no contexto de técnicas de análise de conteúdo (BARDIN, 2004). As informações serão demonstradas a seguir por meio das temáticas descritas anteriormente.

\section{Resultados}

Dentre as atitudes que caracterizam vingança, cita-se o boca a boca negativo (HUEFNER; HUNT, 2000; HUEFNER et al., 2002; BECHWATI; MORRIN, 2003; ZOURRIG; CHEBAT; TOFFOLLI, 2009; FUNCHES; MARKLEY; DAVIS, 2009; GREGOIRE; LAUFER; TRIPP, 2009; THELEN; SHAPIRO, 2012; HOPKINS, 2013; JOIREMAN et al., 2013; LEE; PAN; TSAI, 2013), que pode ser pessoal ou eletrônico (WARD; OSTROM, 2006; ALBUQUERQUE, PEREIRA, BELLINI, 2010; ANDRADE et al., 2010, ANDRADE; BRANDÃO, 2012, ANDRADE; BRANDÃO; BALASSIANO, 2012). O boca a boca negativo, tido como reclamação eletrônica por Ward e Ostrom (2006), foi claro em vários relatos quando da existência do problema, evidenciando uma necessidade latente de transmissão da experiência, com diferentes objetivos, como a justiça social. A maneira como o boca a boca negativo é feito, sendo antes ou depois da reclamação e demonstrando ou não fortes sentimentos negativos, além de suas intenções, o diferencia de um ato tido apenas como retaliatório ou vingativo.

Desde que o problema começou, faço questão de alertar o maior número de pessoas sobre a péssima qualidade dos produtos e do serviço ao consumidor. (Cliente 1)

Vi que essas alternativas de fazer uma propaganda negativa da empresa que me lesou através de redes 
sociais e Reclame Aqui, foi como fazer justiça com as próprias mãos... e funciona muito bem! (Cliente 2)

Coloquei no Facebook da turma (...). Estava doido pra chegar em casa para entrar no Facebook. Fui na fanpage do banco para reclamar, em minha página pessoal também. Divulguei imediatamente quando cheguei. (Focal 1)

Conforme exposto por Grégoire et al. (2010), essa é uma ação vingativa indireta, ocorrendo fora do ambiente de compra, em que os clientes compartilham com amigos e parentes suas más experiências. Nela, há, segundo Huefner e Hunt (2000), a clara intenção de ferir o negócio da empresa, caracterizando-se como vingança (fight). Isso pode ser reforçado pela personalidade, o que Funches et al. (2009) chamam de persona vingativa. Nesses casos, não há a mera intenção de alertar outros consumidores, mas sim de causar obstrucionismo (Funches et al., 2009) ou uma espécie de boicote (ALBUQUERQUE; PEREIRA; BELLINI, 2010):

Não fiz reclamação na [empresa], me arrependo de não ter feito, mas sempre falei mal da [empresa] pra todos os que tenho oportunidade. Consegui levar quase todas as pessoas de meu convívio próximo que também eram [empresa] para a minha atual operadora. (Cliente 11)

Neste relato, é evidente o boca a boca negativo antes da atitude de reclamação, tida como uma importante atitude por parte do consumidor para resolver os problemas com a empresa (HUEFNER; HUNT, 2000) antes de comportamentos retaliatórios ou vingativos. A intenção de causar danos é clara, inclusive pelo estímulo à troca de empresa para a concorrência (e pela quantidade de pessoas). Parece haver um impulso nessa atitude, que pode ter sido provocado por emoções de raiva, pois, conforme Bechwati e Morrin (2003, 2007), a raiva é uma emoção espontânea, diferenciando-se do desejo de vingança por não possuir planejamento para que gere alguma atitude. O relato, pela explicitação de arrependimento e por não ter formalmente reclamado, sugere ainda uma 
tomada de racionalidade por parte do consumidor, mesmo mantendo as atitudes de promoção negativa.

Pode-se perceber, pelos relatos, um crescente aumento do empoderamento de consumidores através de instrumentos de reclamação on-line (WARD; OSTROM, 2006; ALBUQUERQUE et al., 2011; ANDRADE et al., 2013), inclusive com respostas mais rápidas das empresas por meio desses canais. Tais afirmações reforçam outra forma de ação vingativa indireta, citada por Grégoire et al. (2010): a reclamação pública on-line, definida como o ato de usar aplicativos online para alertar o público em geral sobre o mau comportamento de uma empresa (WARD; OSTROM, 2006):

Na época, não tinha essas redes sociais e nem Reclame Aqui. Não pude fazer nada para prejudicar o nome da empresa. (Cliente 2)

Reclamei via SAC sem nenhum tipo de atendimento (9 dias). Depois de reclamar no Twitter, recebi um posicionamento em menos de 24 horas. (Cliente 15)

Mas meu problema só foi solucionado (devolução do meu dinheiro) quando comecei a divulgar no Facebook. Refiz a logomarca da empresa com a palavra [...] e compartilhei. (Cliente 7)

Outra forma de vingança que, embora mais branda, pode significar o que Huefner e Hunt (2000) compreendem como ataque pessoal foi a reação de uma das entrevistadas em relato no grupo focal sobre uma experiência.

Levantei da cadeira e fiz questão de falar bem alto, para que todos ouvissem, inclusive a atendente, o quanto estava sendo mal atendida. Deixei tudo lá, todos aqueles produtos gostosos e mandei irmos embora, eu e minhas amigas. Saí sem pagar. (Focal 3)

Outro fator relacionado à personalidade do consumidor é a presença da persona altruísta, descrita por Funches et al. (2009) como aquele que sente vontade de agir para o bem de outros. Os consumidores 
a seguir afirmam que possuem outras intenções com a divulgação ou ainda por mecanismos formais de proteção: fazer com que os amigos não façam o mesmo.

Tento alertar ao máximo de pessoas possível para não fazer o mesmo que fiz. (Cliente 2)

Apenas quero compartilhar minha má experiência para que outros não passem por isso. (Cliente 11)

Caso tenha que processar, ou mesmo entrar no PROCON, contra qualquer empresa, farei o necessário para impedi-los de abusarem de outros consumidores. (Cliente 4)

O medo apareceu quanto à possibilidade de dividir o caso virtualmente, em vista de represálias advindas da empresa. Isso pode ser associado ao conceito de assimetria de poder, defendido por Aquino et al. (2006), o que faz com que clientes tenham receio a ações de represália, uma vez que aquele com maior poder tende a influenciar de forma mais impactante o bem-estar de outra parta, sendo a empresa, portanto, detentora de maior poder.

Nunca cheguei a falar mal em redes sociais (ainda), pois hoje em dia até olhar feio pra alguém você pode ser processada. Mas sempre falo mal para todos os amigos que tenho. (Cliente 5)

Tal assimetria de poder (AQUINO et al., 2006) também pode servir de desencorajamento para ações mais drásticas, fazendo com que o consumidor acredite "que não vale a pena". A persona vítima (FUNCHES et al., 2009), ou seja, aquela que se sente sem poder sobre comportamentos atuais ou futuros da empresa, é também aqui evidenciada:

Não busquei soluções que iriam me causar grande empenho de tempo, não achei que valesse a pena. (Cliente 3)

A percepção de justiça, nesse caso, é percebida como algo que traz satisfação, prazer e alívio (ZOURRIG, 2009), o que reforça a vingança 
também como uma forte tentativa de aliviar a raiva, sendo tanto um sentimento ou emoção quanto um comportamento cujas consequências geram satisfação, alívio, prazer, reparação psicológica e sensação de felicidade (HUEFNER; HUNT, 2000):

Sempre gostei de resolver esses assuntos na Justiça. Sinto-me superaliviada quando consigo fazer a reclamação, e principalmente quando eles são resolvidos. (Cliente 5)

Sinto certo prazer em relatar a situação e tentar influenciar de forma negativa as pessoas a não comprarem nessa empresa. Em nenhum momento me arrependi de fazer esses comentários. (Cliente 8)

Me senti aliviada, pois eu estava muito irritada com a situação de dependência por uma coisa ridiculamente simples. Mas hoje, refletindo sobre isto, me arrependo de não ter aberto uma reclamação na ouvidoria do banco. (Cliente 10)

Sentimento de alívio. Devido ao péssimo atendimento e falta de informação de como proceder para solucionar o problema, informei ao DECON, Procon e Reclame Aqui. (Cliente 13)

A sensação de arrependimento é encontrada em clientes que não tomam ações formais, mas não em vista de seus comportamentos retaliatórios, como um processo de retomada de racionalidade.

Em momentos cujos atos de reclamação se fazem presente, mas tais reclamações não são atendidas, falas de injustiça são evidenciadas em maior intensidade, apresentando também o fator tempo como catalisador. Sentimentos negativos como a raiva são frequentemente relatados para justificar atos de vingança (BOUGUIE et al., 2003; FUNCHES, 2011). Nos casos a seguir, sentimentos como raiva, revolta, irritação, chateação, percepção de injustiça e arrependimento pela compra estão presentes:

Não resolveu muita coisa! Não vi justiça. (Cliente 2).

Me senti irritada e injustiçada. O único arrependimento é ter comprado nesta loja antes de pesquisar a reputação. 
A justiça ainda não foi feita, e mesmo que seja não vai retirar toda a chateação que estamos passando. (Cliente 1)

Minha mãe está muito revoltada. Além do tempo perdido, raiva e revolta, risco que minha mãe está passando. Uma senhora de 55 anos [...] passar por isso não é justo. Decidimos entrar com processo, e até hoje estamos na luta. Continuamos pagando o valor mensal, não podemos ficar sem o plano. (Cliente 12)

A [empresa] se recusou a pagar os itens que foram extraviados. Entrei com recurso no PROCON e DECON, e depois de um ano e nove meses me foi reembolsado o valor da passagem. (Cliente 15)

Me senti muito chateada, pois fui praticamente roubada. Quando reclamei para outras pessoas, me senti aliviada e fui capaz de tirar aquilo de dentro de mim mais facilmente (me livrar do sentimento de chateação). Entretanto, mesmo agora, quando conto a história, me sinto frustrada pela injustiça que foi cometida. (Cliente 14)

Fiquei com muita raiva e não volto mais para fazer isso. Volto porque tem uma pessoa e vou por ela. não faço nada mais no salão. (Focal 2)

Raiva extrema, chateação pra mim e minha mãe, tempo perdido. hoje nem gosto deste [produto] porque traz lembranças negativas. (Focal 3)

Reclamação a terceiros (GRÉGOIRE, 2008; GRÉGOIRE et al., 2009 e 2010) é definida como o esforço do cliente em consultar uma agência ou advogado para obter assistência, de forma a chegar a um acordo, seja por meio de reclamações em órgãos como o PROCON ou mesmo por meio de processo judicial. Nesses casos, os atos advêm de grandes problemas mal resolvidos. Outra evidência é a ineficácia desses órgãos na representatividade do cumprimento das resoluções pelas empresas, conforme relatos a seguir:

Já fiz um TCO na delegacia contra as enfermeiras da emergência de um hospital, acabei fazendo um acordo, (Cliente 5) 
Vinte anos esperando por justiça é tempo demais para se sentir realizada como cidadã. (Cliente 6)

Duas queixas foram feitas no PROCON e planejamos entrar com uma ação na Justiça Comum. (Cliente 1)

Nessa primeira audiência [com o DECON], nada se resolveu. Na segunda, os representantes propuseram pagar menos da metade do valor pago. Mais uma vez, nada resolvido. (Cliente 12)

Quando tinha tempo, antigamente, ia ao PROCON. Agora, sem tempo, não [vou]. Antigamente, fazia mais. (Focal 1)

Foram evidenciadas ações por parte das empresas que, pelos relatos, sugeriram culpa por parte do consumidor. Reforça-se a atribuição de culpa da empresa como um forte antecedente de ações vingativas, alertando para uma possível estratégia utilizada pelas empresas a fim de se eximirem de suas responsabilidades. Segundo Funches (2011), a causalidade pode ser a chave do retorno de clientes, pois atribuir a culpa para a empresa ou de forma individual conduz a diferentes respostas comportamentais dos consumidores:

Fui ao PROCON, porém, eles alegaram que no bilhete do passageiro tinha um aviso de que a empresa não era responsável por pertences de valor na mala. Já para o caso do notebook, expus o ocorrido pelo Facebook e, além disso, deixei relatos no Reclame Aqui. (Cliente 2)

Nesse caso, as atitudes da empresa em resposta, quando não resolvem os problemas causados para o consumidor, acabam por contribuir para os comportamentos retaliatórios em maior ou em menor grau. O rompimento do relacionamento e o afastamento foram outras grandes consequências encontradas. A intenção de não retornar (ou afastamento) foi latente:

Desde o ocorrido, não consumi e nem planejo consumir nada nesta loja (...). Planejo evitar fazer compras nas grandes lojas de magazine, pois a maioria é conhecida pelos mesmos problemas. (Cliente 1)

Não voltei a ser cliente e mudei de hospital. Não pretendo 
voltar, a não ser que tenha alguém da minha família ou amigos queridos por lá. Espero que não. (Cliente 5)

Acredito que não consumirei mais nenhum produto dessa loja e penso que continuarei influenciando negativamente sua imagem. (Cliente 8)

Minha confiança na empresa acabou com esse episódio. (Cliente 9)

Não acredito mais em seus produtos. (Cliente 13)

Não voltei a ser cliente e mudei para a concorrência. (Cliente 11)

A sensação de alívio depois que tomei a providência... Não voltaria mais, mesmo que só tivesse essa. Fiquei com repúdio. Não gosto, não vou mais. É uma questão de orgulho. Eu constrangi e faria de novo, mas não volto por isso que fiz. Também fiquei constrangida. (Focal 3)

Procurar o concorrente é uma atitude encontrada após atos de vingança, podendo levar os clientes a consumirem mais que o planejado, pois quando o desejo de vingança é alto, muitos consumidores optam por deixar a empresa e escolhem empresas competidoras, mesmo que disponham de altos preços (BECHWATI; MORRIN, 2003), principalmente se elas oferecem vantagens competitivas:

Evito o máximo usar novamente seus serviços, nem que isso custe pagar mais caro nas empresas concorrentes. (Cliente 15)

No mesmo dia, fui muito bem recebido e atendido na [loja concorrente] e cheguei até a consumir um valor maior ao que tinha planejado inicialmente. (Cliente 8)

Comprei um notebook da concorrente [produto], pois tem um sistema de garantia a domicílio em $24 \mathrm{~h}$ após relato do problema. (Cliente 2)

Se pudesse trocar, eu trocaria, mas não podia, tinha vínculo institucional. (Focal 1)

O funcionário é reconhecido, em alguns casos, como peçachave nas situações em que experiências desagradáveis de consumo são experimentadas (FUNCHES, 2011), corroborando com a pesquisa 
de Plutarco et al. (2012). Observou-se que ou as organizações estavam cientes da situação, mas não tomaram atitudes efetivas, ou buscaram atribuir a culpa para o funcionário.

Senti que não precisaria chegar ao ponto de me exasperar [...]. Quem perde é o funcionário, pois deixa de receber o mérito de resolver o problema sem atrito. Devemos alcançar esferas mais altas nas empresas antes de ações mais drásticas. Talvez estas pessoas tenham a visão e autoridade para resolvê-las. (Cliente 4) Cheguei lá, relatei toda a situação para a gerente, que, para minha surpresa, não estava atendendo a ninguém e muito menos sabendo do ocorrido (segundo ela, né?). (Cliente 10)

Embora alguns tenham continuado clientes das empresas ofensoras, é importante salientar o alerta feito por Funches (2011) de que esses consumidores passam a tomar medidas para reduzir sua dependência dessas empresas, como a busca por alternativas substitutas e/ou redução da tolerância a erros futuros, fazendo dessas mudanças de comportamento uma forma de "punição". É o comportamento tido como flight, ou seja, mais passivo, como colocam Zourrig et al. (2009). O retorno às empresas também foi evidenciado quando uma resolução foi apresentada eficazmente pela empresa:

Ainda sou correntista, mas estou aguardando uma próxima ocasião em que precisarei do banco para ver se o atendimento melhora ou não. Mas, com certeza, após isto, já estou pesquisando outros bancos que me ofereçam vantagens iguais ou melhores, para que eu não fique refém na mão de ninguém. (Cliente 10)

Da [empresa], sim... Não temos muitas alternativas para viajar no Brasil... Qualquer promoção é sempre bem-vinda! Sempre tenho cuidado de não despachar nada de valor junto com a mala. (Cliente 2 )

Por uma postura responsável das empresas ao apresentar uma solução ou um pedido de desculpas de verdade, mais do que apenas palavras [...]. Voltei a ser 
cliente de todas as empresas que resolveram o problema que iniciou desagradável. (Cliente 3 )

A [empresa] me fidelizou depois do acontecido, oferecendo descontos e vários tipos de regalias. Voltei a fazer negócio. (Cliente 15)

Voltaria a comprar porque a empresa tem uns voos muito baratos. (Focal 3)

Fatores relacionados à personalidade e idade foram motivos de discussão no grupo focal como fatores que influenciam os comportamentos retaliatórios. Huefner e Hunt (2000) observaram fatores como idade, grau de instrução e gênero e sua interferência nesta relação.

Acho que o envelhecimento protege a gente, quando era mais novo pensava assim (Focal 4).

Não acho que seja questão só de idade, mas também de personalidade (Focal 3).

Não porque quando era mais novo era assim e eu aprendi isso, porque a gente procura atalhos e consegue ser mais feliz, tem gente que busca problema, se tenho certeza que tá errado, não vou atrás (Focal 4).

Quem é assim é mais feliz, porque evita problema, do contrario você fica remoendo, penso tanto que eu brigo (Focal 3).

Observa-se, portanto, que comportamentos retaliatórios ou vingativos podem ser tomados antes ou depois de comportamentos de reclamação. Tais comportamentos aprimoraram-se pelo crescimento de mecanismos virtuais públicos. Isso se verifica por uma forte e latente necessidade do consumidor de transmitir seus sentimentos, seja de forma espontânea e imediata (motivados por raiva), seja de forma posterior, mesmo com o problema já racionalizado (significando a mensuração do desejo de vingança). No caso da racionalização, ocorre o arrependimento apenas pela possível falta de atitudes formais e diretas antes da vingança, arrependimento este que não se verificou após tais atos, caracterizando a certeza dos consumidores por suas atitudes. 
Esses consumidores acabam por se afastar dessas empresas e procurar a concorrência. Grande parte deles não retoma essas relações desgastadas, cuja confiança foi quebrada. Uma parte, porém, em vista do oferecimento de novas garantias ou mesmo pela inexistência de concorrência tida como diferencial, acaba por se manter ou voltar ao consumo.

Como se pode constatar, não foram evidenciados outros tipos de atos de vingança, estudados por Huefner e Hunt (2000) como atos de vandalismo, desordem ou roubo. Essa é mais uma evidência de que os meios virtuais se tornaram fontes de busca de equidade e empoderamento por parte do consumidor.

\section{Considerações finais}

Esta pesquisa buscou analisar o comportamento de consumidores após atitudes de vingança, a fim de identificar seus potenciais consequentes. Os resultados confirmam as expectativas teóricas sobre antecedentes, como a insatisfação, a percepção de injustiça, a raiva, o desejo de vingança, além de atitudes vingativas. Corroboram ainda mais para o início do desvelar da lacuna existente na literatura para os consequentes de atitudes de vingança no contexto do comportamento do consumidor.

A contribuição deste trabalho reside em corroborar, em contexto brasileiro de estudos, aspectos relacionados aos antecedentes, às formas mais utilizadas como retaliação ou vingança (marcadas por atos virtuais) e evidenciar consequentes relacionados ao comportamento de vingança por parte dos consumidores em ambientes reais de compra, e não somente em ambientes virtuais. Contribui ainda com a proposição de constructos como o desejo de afastamento e desejo de reconciliação como mediadores, respectivamente, entre as atitudes de afastamento e reconciliação. Em contexto gerencial, visa contribuir para a recuperação/ manutenção de relacionamento entre empresas e clientes. 
Observou-se que atos de retaliação e vingança diferem não exatamente em termos de tipos de atitudes, como relatado em estudos anteriores (ALBUQUERQUE; PEREIRA; BELLINI, 2010, ANDRADE; BRANDÃO; BALASSIANO, 2013), mas em termos de intensidade de cognições e sentimentos antecedentes. O que se observa, por exemplo, em atos de reclamação que podem ser evidenciados apenas como atos formais de explicitação do problema ou atos com objetivos de gerar danos e podem ser feitos diretamente às empresas ou por mecanismos públicos ou virtuais.

Neste estudo, o boca a boca negativo, as reclamações vingativas, as reclamações públicas on-line, as ações em órgãos de defesa do consumidor e os processos judiciais delinearam-se como as grandes ações vingativas empenhadas por consumidores que se sentiram injustiçados e motivados por fortes sentimentos negativos. Além disso, como consequência de desejos e atitudes de afastamento, observouse a busca pela concorrência de forma latente. Ainda assim, alguns consumidores, em vista de dadas ações por parte das empresas, demonstram certa flexibilidade de retorno, o que reforça a observância do desejo e a atitude de reconciliação. O aparecimento dos elementos medo, tempo, personalidade e idade como moderadores em comportamentos vingativos de consumidores também são achados importantes que merecem aprofundamento posterior, servindo de ferramentas gerenciais para as empresas.

Outra evidência importante foi a percepção de ineficácia pelos consumidores de instrumentos judiciais frente à sua defesa, sendo os mecanismos virtuais canais emergentes para a busca de soluções ou resgate da equidade na relação e, por conseguinte, contribuindo para o aumento da sensação de empoderamento destes.

Como limitação, a literatura predominante neste tema vem de áreas distintas, como a Psicologia e o Direito, tendo suas pesquisas aplicadas em contextos de prisão, funcionários de empresas e estudantes universitários, ampliando a necessidade de exploração no contexto de consumi, de modo particular em consumidores nos 
ambientes reais de compra, e não somente nos virtuais. A literatura também é predominantemente americana, fortalecendo a necessidade de expansão dos estudos transculturais de trocas comerciais. Outra limitação seria a impossibilidade de generalização dos resultados apresentados a partir do estudo qualitativo, pois o pequeno número de respondentes pode não caracterizar o universo do estudo proposto. Outra limitação foi o não encontro de percepções de culpa ou arrependimento por parte do consumidor pós-atitudes vingativas e que causassem o desejo de reconciliação (e consequentemente, o ato de reconciliação). Houve ainda a impossibilidade de evidenciação de diferentes gravidades de atitudes, para que estas pudessem ser diferenciadas em atitudes de retaliação ou vingança. Isso evidencia a necessidade de exploração por intermédio de fatores moderadores, como idade, gênero, grau de instrução, cultura (alocêntrica e idiocêntrica), personalidade (vingativa, altruísta e vítima), e outros relacionados à cognição emoção e atitude, como parte de um estudo descritivo, de caráter quantitativo.

Como implicação acadêmica, observa-se o extrapolar de barreiras até então estudadas e consequente necessidade de aprofundamento de um modelo que enquadre antecedentes e consequentes, bem como os efeitos mediadores citados anteriormente. Um estudo disposto inclusive a observar diferenças transculturais. Portanto, o desenvolvimento de uma escala que englobe tais fatores se dá como sugestão para pesquisas futuras. O aprofundamento acadêmico do tema visa, assim, relacionar constructos de outras áreas, principalmente na Psicologia.

\section{Referências}

AlBuquerque, F. M. F.; PEREIRA, R. C. F.; BELLINI, C. G. P. Do repertório de comportamentos do consumidor: retaliação e vingança no ciberespaço. R. Adm., São Paulo, v.46, n.2, p.135-149, abr./maio/jun. 2011.

ANDRADE, D. M.; BALASSIANO, M.; BRANDÃO, M. M. Modelo estrutural do comportamento de retaliação e vingança do consumidor 
insatisfeito. Revista Brasileira de Marketing - REMark, São Paulo, v. 12, n. 1, p. 51-72, jan./mar., 2013.

ANDRADE, D. M.; BRANDÃO, M. M.; PEREIRA, S. J. N.; CUNHA, E. $S$. Clicando e reclamando: uma análise de consumidores insatisfeitos com compras online. In: Seminários em Administração - Semead, XVIII, 2010. São Paulo. Anais... São Paulo: FEA-USP, 2010.

ANDRADE, D. M.; BRANDÃO, M. M. Boca a Boca Eletrônico como Forma de Retaliação: uma aplicação de modelagem de equações estruturais para determinar o comportamento pós-reclamação de consumidores insatisfeitos-ofendidos. Revista ADM.MADE, Rio de Janeiro, v.16, n.1, p.24-2, janeiro/abril, 2012.

AQUINO, K.; TRIPP, T.; BIES, R. How employees respond to personal offense: the effects of blame attribution, victim status, and offender status on revenge and reconciliation in the workplace. Journal of Applied Psychology, v.86, n.1, p.52-59, February 2001.

AQUINO, K.; TRIPP, T.; BIES, R. Getting Even or Moving on? Power, Procedural Justice, and Types of Offense as Predictors of Revenge, Forgiveness, Reconciliation, and Avoidance in Organizations. Journal of Applied Psychology, v.91, p. 653-658, May 2006.

BARDIN, L. Análise do conteúdo. Lisboa: Edições 70, 2004.

BECHWATI, N. N.; MORRIN, M. Understanding Voter Vengeance. Journal of Consumer Psychology, v.17, n.4, p. 277-291, October 2007.

BECHWATI, N. N.; MORRIN, M. Outraged Consumers: getting even at the expense of getting a good deal. Journal of Consumer Psychology, v.13, n.4, p.44-53, 2003.

BOUGIE, R.; PIETERS, R.; ZEELENBERG, M. Angry Customers Don't Come Back, They Get Back: the experience and behavioral implications of anger and dissatisfaction in services. Journal of the Academy of Marketing Science. v.31, n.4, p.377-393, 2003. 
CARVALHO, S. W.; SEN, S.; MOTA, M. O.; LIMA, R.C. Consumer Reactions to CSR: A Brazilian Perspective. Journal of Business Ethics, v.91, Issue 2 Supplement, p.291-310, February 2010.

CRONIN JR., J. J. Looking back to see forward in services marketing: some ideas to consider. Managing Service Quality, v. 13, n. 5, p. 332$337,2003$.

FERNANDES, D.; SANTOS, C. As Consequências Comportamentais da Insatisfação dos Clientes. RAC, Curitiba, v.12, Edição Especial, p.147174, 2008.

FUNCHES, V. The consumer anger phenomena: causes and consequences. Journal of Services Marketing, v.25, n.6, p.420-428, 2011.

FUNCHES, V.; MARKLEY, M.; DAVIS, L. Reprisal, retribution \& requital: investigating customer retaliation. Journal of Business Research, v.62, n.2, p.231-239, February 2009.

GIGLIO, E.A.M.; CHAUVEL, M.A. Reclamação e cultura brasileira: um estudo baseado na análise de cartas de consumidores insatisfeitos à imprensa. In: Encontro de Pós-Graduação em Administração (EnANPAD), XXVI, 2002, Salvador. Anais... Salvador: EnANPAD, 2002.

GRÉGOIRE Y.; FISHER, R. Customer Betrayal and Retaliation: When Your Best Customers Become Your Enemies. Journal of the Academy of Marketing Science, Volume 36, Issue 2, p.247-261, June 2008.

GRÉGOIRE, Y.; LAUFER, D; TRIPP, T. A Comprehensive Model of Customer Direct and Indirect Revenge: understanding the Effects of Perceived Greed and Customer Power. Journal of the Academy of Marketing Science, v.38, n.6, p.738-58, Frebuary 2010.

GRÉGOIRE, Y.; LAUFER, D.; TRIPP, T.; LEGOUX, R. When Customer Love Turns into Lasting Hate: The Effects of Relationship Strength and Time on Customer Revenge and Avoidance. Journal of Marketing, v.73, n.6, p.18-32, November 2009. 
HOPKINS, L. Revenge or Reconciliation? A Rejection-Based Model of Firm-Induced Relationship Termination. 2013. 87f. Dissertations (MBA Management), Theses and Capstone Projects. Paper 581. Kennesaw State University, 2013.

HUEFNER, J. C.; HUNT, H. K. Consumer retaliation as a response to dissatisfaction. Journal of Consumer Satisfaction, Dissatisfaction and Complaining Behavior, University of Nevada Las Vegas, v.13, p. 61-82, 2000.(volume anual)

HUEFNER, J. C.; HUNT, H. K.; PARRY, L.B.; PAYNE, C. R.; OTTO, S. D.; HUFF, S.C.; SWENSON, M. J. Consumer retaliation: confirmation and extension. Journal of Consumer Satisfaction, Dissatisfaction \& Complaining Behavior, University of Nevada Las Vegas, v.15, p.114127, 2002..(volume anual)

JOIREMAN, J.; GREGOIRE, Y.; DEVEZER, B.; TRIPP, T. When do customers offer firms a "second chance" following a double deviation? The impact of inferred firm motives on customer revenge and reconciliation. Journal of Retailing, v.89, n.3, p.315-337, September 2013.

KALAMAS, M.; LAROCHE, M.; MAKDESSIAN, L. Reaching the boiling point: Consumers' negative affective reactions to firm-attributed service failures. Journal of Business Research, v.61, n.8, p.813-824, August 2008.

LEE, JIN-SOO; PAN,S.; TSAI, H. Examining perceived betrayal, desire for revenge and avoidance, and the moderating effect of relational benefits. International Journal of Hospitality Management, v.32, n.1, p.80-90, March, 2013.

MALHOTRA, N. K. Pesquisa de Marketing: uma orientação aplicada, 6 ed., Porto Alegre: Bookman, 2012.

MARCONI, M. A.; LAKATOS, E. M. Fundamentos de metodologia científica. 5 ed., São Paulo: Atlas, 2003. 
MATTILA, A. S.; WIRTZ, J. Consumer complaining to firms: the determinants of channel choice. Journal of Services Marketing, v.18, n.2, p.147-155, 2004.

MCCULLOUGH, M. E.; RACHAL, K. C.; SANDAGE, S. J.; WORTHINGTON, E. L.; BROWN, S. W.; HIGHT, T. L. Interpersonal forgiving in close relationships. II: Theoretical elaboration and measurement. Journal of Personality and Social Psychology, v.75, n.6, p.1586-1603, Dec. 1998.

OLIVEIRA, M.; FREITAS, H. Focus group: instrumentalizando o seu planejamento. In: GODOI, C. K.; BANDEIRA-DE-MELLO, R.; SILVA, A. B. (Org.). Pesquisa qualitativa em estudos organizacionais: paradigmas, estratégias e métodos. São Paulo: Saraiva, 2006. p. 325346.

PLUTARCO, F.; FREITAS, A. A. F.; MOTA, M. Understanding Consumers' reactions to service failures: an Attribution Theory Perspective. Journal of Service Research, v.15, n. 3, p. 296-315, August 2012.

ROSSI, P. C. Modelos culturais e o comportamento de retaliação do consumidor. 2011. 141 f. Dissertação (Mestrado apresentada ao programa de pós-graduação em administração) - Universidade Federal do Rio Grande do Sul, Porto Alegre, 2011.

SANTOS, C. P.; FERNANDES, D. A construção de uma tipologia dos consumidores para resposta à insatisfação. Revista de Administração e Contabilidade da Unisinos, v.7, n.1, p.25-41, Janeiro/Março, 2010.

STUCKLESS, N.; GORANSON, R. The Vengeance Scale: Development of a Measure of Attitudes Toward Revenge. Journal of Social Behavior and Personality, v.7, n.1, p.25-42, Jan.1992.

STUCKLESS, N.; FORD, D. B.; VITELLI, R. Vengeance, anger and irrational beliefs in inmates: a caveat regarding social Desirability. Personality and Individual Differences, v.18, n.1, p.1-6, January 1995. 
TAX, S.; BROWN, S.; CHANDRASHEKARAN, M. Customer evaluations of service complaint experiences: implications for relationship marketing. Journal of Marketing, v.62, n.2, p.60-76, April 1998.

THELEN, S.; SHAPIRO, T. Predicting negative consumer reactions to services offshoring. Journal of Services Marketing, v.26, n.3, p.181193, 2012.

VERO, J. Paixões estrangeiras: a vingança. 2013. 208f. Tese (Doutorado em psicologia clínica). Pontifícia Universidade Católica de São Paulo, São Paulo, 2006. Disponível em <http://www.sapientia. pucsp.br>. Acesso em: 19 dez. 2013.

WARD, J. C.; OSTROM, A. L. Complaining to the masses: the role of protest framing in customer-created complaint web sites. Journal of Consumer Research, v.33, n.2, p.220-230, Jul. 2006.

ZOURRIG, H.; CHEBAT, J.; TOFFOLI, R. Consumer revenge behavior: a cross-cultural perspective. Journal of Business Research, v.62, n.10, p.995-1001, October 2009.

ZOURRIG, H. Three essays on consumer revenge, avoidance and Forgiveness behaviors: a cross-cultural perspective. 2010. 148 f. Tese (Pós Doutourado em Administração). HEC Montréal, Universidade de Montreal, Canadá, 2010.

Artigo recebido em: 25/08/2014

Aprovado em: 06/11/2014 